\title{
Development of an open-loop ground source cooling system for space air conditioning system in hot climate like Indonesia
}

\author{
Jalaluddin ${ }^{1, *}$, Akio Miyara ${ }^{2}$, Shohei Ishikawa ${ }^{3}$, Rustan Tarakka ${ }^{1}$ and Andi Amijoyo \\ Mochtar $^{1}$ \\ ${ }^{1}$ Department of Mechanical Engineering, Hasanuddin University, Bontomarannu, 92171 Gowa, \\ Indonesia \\ ${ }^{2}$ Departement of Mechanical Engineering, Saga University, 1 Honjomachi, 840-8502 Saga-shi, Japan \\ ${ }^{3}$ Oriental Consultants Global Co., Ltd. Japan
}

\begin{abstract}
Ground source cooling system (GSCS) is promising technology to serve cooling demands of buildings. This study presents a development of an open-loop GSCS for space air conditioning at Hasanuddin University Gowa campus. Experimental study was carried-out by pumping water from well of $57 \mathrm{~m}$ depth and flowing the water over a heat exchanger to cool refrigerant of air conditioning (AC) unit. The performance of AC unit was investigated under actual operation with various water flowrates. The temperatures of inlet and outlet water in the heat exchanger were also measured. The system operated from 11:00 until 18:00 o'clock local time with 3 (three) flowrates such as 3.6; 6.5 and $14.3 \mathrm{~L} / \mathrm{min}$ respectively. In the low flowrate, the temperature of outlet water is approximately $37{ }^{\circ} \mathrm{C}$. However, the compressor power is also increase significantly. The coefficient of performances (COPs) of the system in average are 2.9 in the low flowrate and 3.4 in the high flowrate. Also. the result shows that the utilization of GSCS is appropriated for cooling buildings in the hot climate like Indonesia.
\end{abstract}

\section{Introduction}

Ground source heat pump (GSHP) system consists of closed-loop and open-loop ground heat exchanger (GHE) used in the system. In the closed-loop system, vertical and horizontal types are applied in this system. The vertical types have been used widely in the GSHP system which is a number types of pipe configurations placed in the vertical borehole. Various types of vertical GHEs including U-tube, double-tube, multi-tube [1-3] and spiral tube $[4,5]$ have been investigated. The spiral tube GHE provided a better thermal performance. An open-loop system is generally characterized by a lower initial cost and higher coefficient of performance (COP). The GSHP system used for cooling system is also known as ground source cooling system (GSCS). The advantage of application of openloop GSCS is the more stable of groundwater temperature over the year than the air

*Corresponding author: jalaluddin_had@yahoo.com 
temperature used in conventional air conditioning system. Two wells are provided in this system including one well used for groundwater extraction and the other used for injection. Geothermal wells are of great interest in the cooling demand of building with utilizing the groundwater as a thermal reservoir instead of the atmosphere.

A number of studies related to open-loop GSCS have been conducted. A comprehensive analysis of the thermal response of open-loop wells for ground coupled heat pump systems was conducted by Woods and Ortega [6]. Park et al. [7] describes the importance of thermal dispersivity in designing groundwater heat pump (GWHP) systems. Athresh et al. [8] presented a novel design and implementation of an open-loop system of GSHP operating in an ochre rich mine water environment. The results show that open-loop systems, when combined with suitable heat pump and the associated design configurations of heat exchangers and maintenance procedures, could provide an efficient and reliable heating system at a lower cost. Nguyen et al. [9] presented a dynamic 2D axisymmetric thermal resistance and capacity model (TRCM) that couples transient heat transfer and groundwater flow in a SCW system. Thermal conductivity characteristics of a well-type underground heat exchanger with respect to the amount of injected heat per meter were investigated by Lee et al. [10]. The method to simulate groundwater flow and heat transfer in complex hydrogeological conditions for standing column well (SCW) system, pumping and injecting groundwater in single borehole among ground source heat pump (GSHP) systems was presented [11]. In addition, performance analysis of GSCS with horizontal GHE conducted by Naili et al. [12] in Tunisia and showed that the utilization of the GSCS is appropriated for cooling building in Tunisia, which is characterized by a hot climate.

In this present research, an open-loop GSCS for space air conditioning were developed at Hasanuddin University Gowa campus. Experimental study was carried-out by pumping water from well of $57 \mathrm{~m}$ depth and flowing the water over a heat exchanger to cool refrigerant of air conditioning (AC) unit. The system operated with 3 (three) flowrates such as 3.6; 6.5 and $14.3 \mathrm{~L} / \mathrm{min}$ respectively.

\section{Experimental set-up}

This research was conducted in Renewable Energy Laboratory, Mechanical Engineering Department of Hasanuddin University at the position of $119^{\circ} 30^{\prime} 06.1^{\prime \prime}$ E and $05^{\circ} 13^{\prime} 52.4^{\prime \prime}$ $\mathrm{S}$. The open-loop GSCS consists of two open-loop wells. Water was pumped from the well of $57 \mathrm{~m}$ depth, flow the water through a heat exchanger to cool refrigerant of AC unit and return it to the other well of $50 \mathrm{~m}$ depth. The water flow through the heat exchanger was set with various flowrates. The installation of the open-loop GSCS at the Building of Mechanical Engineering Departement can be seen in Figure 1. The AC unit using in this experimental study is split type with cooling capacity of $2620 \mathrm{~W}$. Experimental set-up of the system is shown in Figure 2.
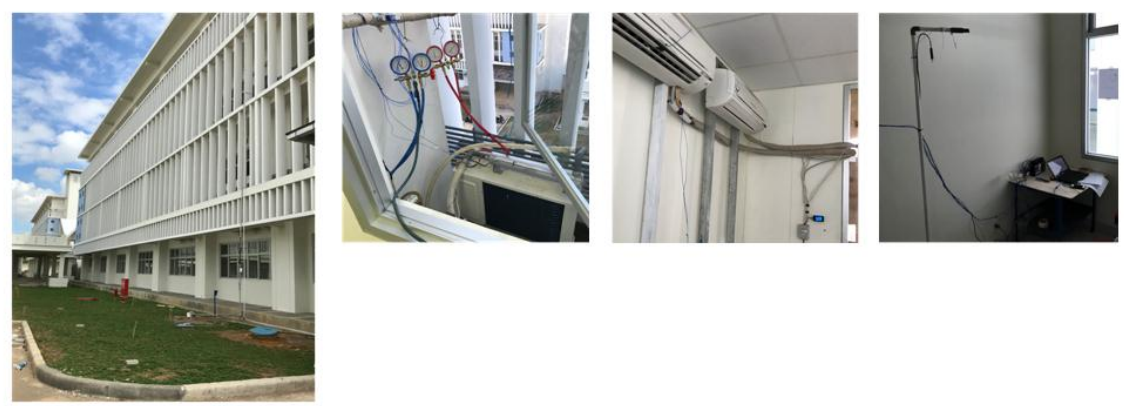

Fig. 1. Installation of the Open-loop GSCS. 


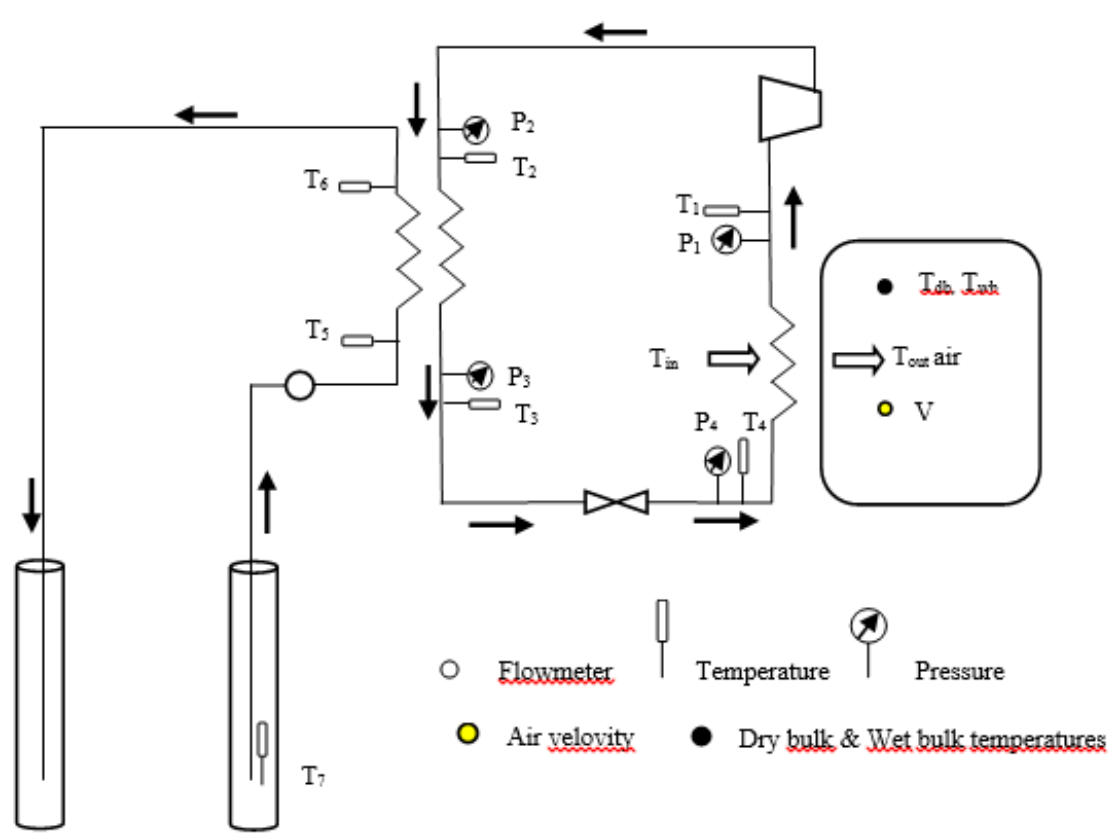

Fig. 2. Experimental Set-up of the Open-loop GSCS.

\section{Results and Discussion}

\subsection{Water and ambient air temperatures}

Water pumped from the well flows through the heat exchanger to cool refrigerant of AC unit. Temperatures of inlet and outlet water are shown in Figure 3. Temperature of inlet water is almost constant of $28{ }^{\circ} \mathrm{C}$. However, temperature of outlet water varies depend on its flowrate. Lowering the flowrate will increase the outlet water temperature. In the low flowrate of $3.6 \mathrm{~L} / \mathrm{min}$, the temperature of outlet water is approximately $37^{\circ} \mathrm{C}$. The ambient air temperature within the operation of the system is also shown in Figure 3. It is approximately from $28-32{ }^{\circ} \mathrm{C}$.

\subsection{Compressor power}

Figure 4 shows the compressor power in the operation of various flowrates. The power of compressor will significantly affect the performance of AC unit. It decreases with increasing the water flowrate enter to the heat exchanger. The compressor powers in average are $689 \mathrm{~W}$ in the low flowrate and $600 \mathrm{~W}$ in the high flowrate. It increases of $15 \%$ with lowering the flowrate from 14.3 to $3.6 \mathrm{~L} / \mathrm{min}$. 

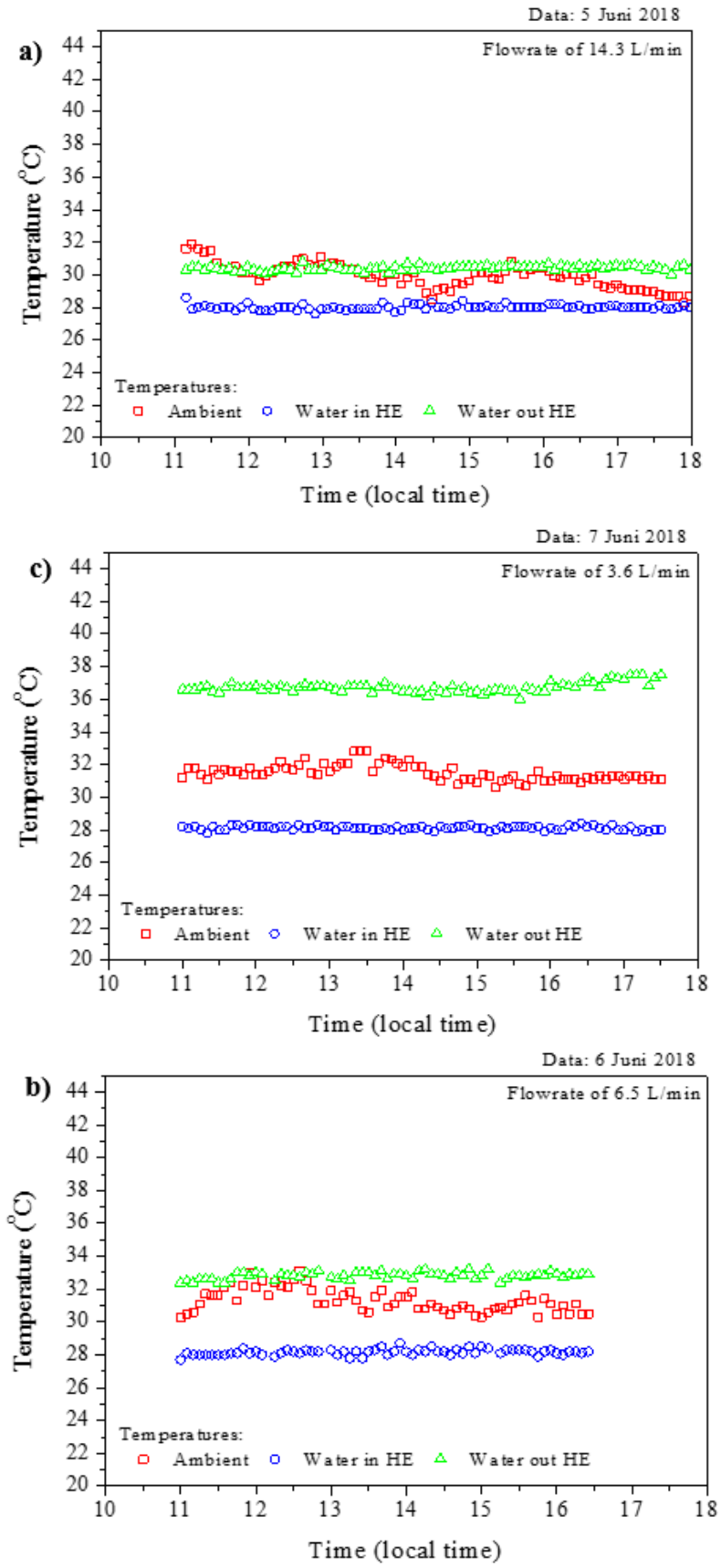

Fig. 3. Water and Ambient Air Temperatures. 


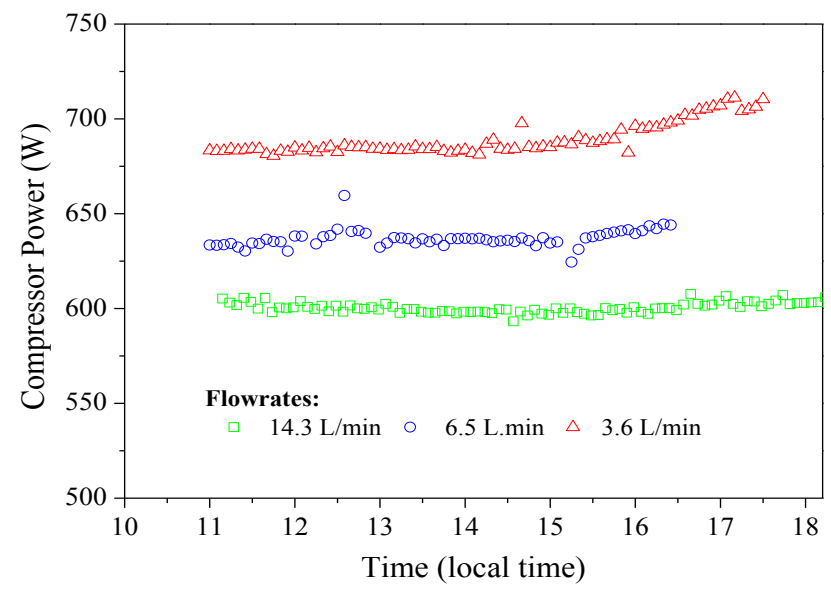

Fig. 4. Compressor Power.

\subsection{Coefficient of performance (COP)}

The performance of open-loop GSCS was affected significantly by the water flowrate enter the heat exchanger. Coefficient of performances (COPs) of the open-loop GSCS in the operation of various flowrate are shown on Figure 5. The COPs of the system in average are 2.9 in the low flowrate and 3.4 in the high flowrate.

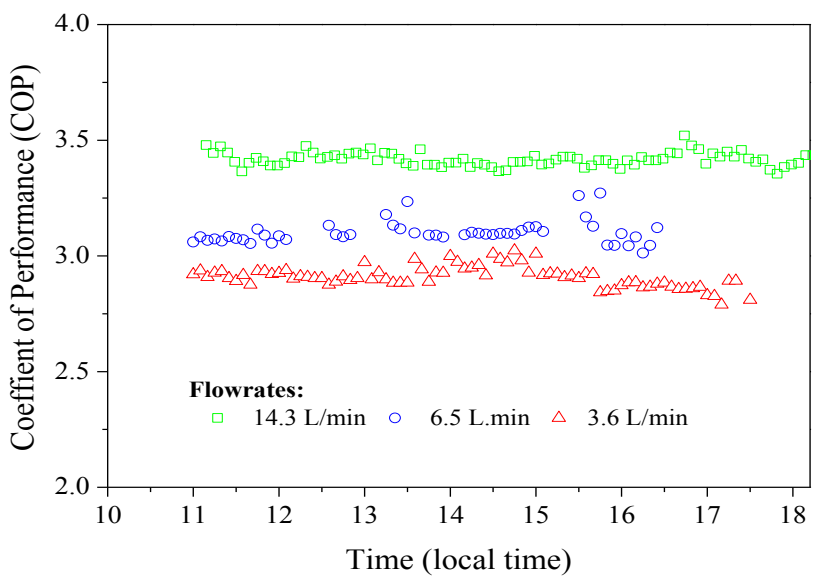

Fig. 5. Coefficient of Performance (COP) of the Open-loop GSCS.

\section{Conclusions}

The experimental study of an open-loop GSCS for space air conditioning at Hasanuddin University Gowa campus has been conducted to investigate the thermal performance of the system. The system operated from 11:00 until 18:00 o'clock local time with 3 (three) flowrates such as $3.6 ; 6.5$ and $14.3 \mathrm{~L} / \mathrm{min}$ respectively. From the results of this study, the following conclusions are drawn:

1) In the low flowrate, the temperature of outlet water is approximately $37{ }^{\circ} \mathrm{C}$. However, the compressor power is also increase significantly. 
2) The compressor power increases of $15 \%$ with lowering the flowrate from 14.3 to 3.6 $\mathrm{L} / \mathrm{min}$.

3) The COPs of the system in average are 2.9 in the low flowrate and 3.4 in the high flowrate.

4) The utilization of GSCS is appropriated for cooling buildings in the hot climate like Indonesia.

This research was financially supported by Japan International Cooperation Agency (JICA) C-BEST Research Project and technically supported under the Memorandum of Agreement between Hasanuddin University Faculty of Engineering and ACKG, Japan.

\section{References}

1. Jalaluddin, A. Miyara, K. Tsubaki, S. Inoue, K. Yoshida, Ren. Energy, 36, 764-771 (2011)

2. Jalaluddin, A. Miyara, ATE, 33-34, 167-174 (2012)

3. Jalaluddin, A. Miyara, JESTEC, 11(12), 1771-1783 (2016)

4. Jalaluddin, A. Miyara, ATE, 90, 630-637 (2015)

5. Jalaluddin, A. Miyara, R. Tarakka, JMeche (2018)

6. K. Woods, A. Ortega, Int. J. Heat Mass Transfer, 54, 5574-5587 (2011)

7. B.H. Park, G.O. Bae, K.K. Lee, Ren. Energy, 83, 270-279 (2015)

8. A.P. Athresh, A. Al-Habaibeh, K. Parker, Int. J. Coal Geol. (2015)

9. A. Nguyen, P. Pasquier, D. Marcotte, Ren. Energy, 76, 743-756 (2015)

10. C. Lee, J. You, H. Park, ENB (2018)

11. T. Choe, I Ko, ENB, 163, 140-148 (2018)

12. N. Naili, M. Hazami, I. Attar, A. Farhat, J. Energy, 61, 319-331 (2013) 